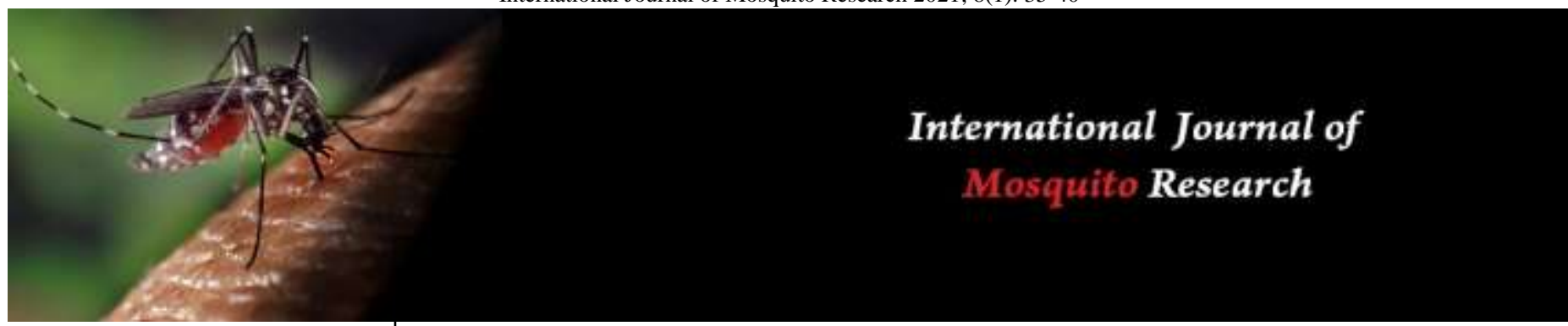

ISSN: 2348-5906

CODEN: IJMRK2

IJMR 2021; 8(1): 35-40

(C) 2021 IJMR

www.dipterajournal.com

Received: 25-10-2020

Accepted: 18-12-2020

Athira A

Biopesticides and Toxicology

Laboratory, Department of

Zoology, University of Calicut,

Malappuram, Kerala, India

\section{E Pushpalatha}

Biopesticides and Toxicology Laboratory, Department of Zoology, University of Calicut, Malappuram, Kerala, India
Corresponding Author: E Pushpalatha

Biopesticides and Toxicology Laboratory, Department of Zoology, University of Calicut, Malappuram, Kerala, India

\section{Essential oils of a few aromatic plants and their potential as knockdown, repellent and adulticidal agent to the filarial vector, Culex quinquefasciatus Say (Diptera: Culicidae)}

\author{
Athira A and E Pushpalatha \\ DOI: https://doi.org/10.22271/23487941.2021.v8.i1a.498
}

\section{Abstract}

Use of synthetic products for the control of mosquito vectors raises serious concern about their negative impact on the environment, non-target organisms and human safety. Alternatively, the use of several natural products, particularly plant based essential oils have gained attention due to their good efficacy and ecofriendly nature. The adult knockdown effect and repellent activities of essential oils derived from three selected plants on Culex quinquefasciatus were evaluated. Data processing was performed using probit analysis. The results showed that essential oils from all the selected plants exhibited considerable knockdown effect on $C x$. quinquefasciatus. In addition to this, all plant derived essential oils showed repellent activity which was significant in all concentrations. It is suggested that essential oils derived from Citrus limon were found to be very active as mosquito repellent.

Keywords: Mosquito vector, essential oils, repellent activity, Culex quinquefasciatus, knockdown, Citrus limon, Cinnamomum verum, Lantana camara

\section{Introduction}

Mosquitoes are considered as the most concerned insect groups of public health importance owing to their capability of spreading several diseases ${ }^{[1,2]}$ and these mosquito-borne diseases induce major health problems in developing countries at large extent ${ }^{[3]}$. In addition to the spreading of diseases they are considered as human pests causing allergic responses including skin reactions ${ }^{[4]}$. In the past decades insecticides of chemical origin have been considered as effective against mosquito vectors and constant application of chemical insecticides including organophosphates is generally undertaken to eradicate mosquitoes ${ }^{[5]}$. The extensive and continuous application of these chemicals induced resistance in mosquitoes followed by the resurgence of mosquito-borne diseases ${ }^{[6]}$. Moreover, repeated usage of chemical insecticides leads to undesirable effects on non-target organisms ${ }^{[7,8]}$.

In the light of increased resistance of mosquitoes against chemical insecticides, plant derived compounds are used as an alternative to chemical insecticides ${ }^{[9]}$. Essential oils extracted from plants have been widely used as mosquito repellents and provide considerable protection from the deadly vector mosquitoes ${ }^{[10,11,12,13]}$. Many studies have been supported the anti-insect potential of several plant based essential oils ${ }^{[14,15,16]}$. Essential oils have received much attention due to the presence of potential bioactive compounds which can be effectively used against insect pests ${ }^{[17]}$.

Cheng et al. ${ }^{[18]}$ reported that several essential oils exhibit strong mosquito repellent and larvicidal activity in addition to their promising inhibitory effects against bacteria, termites and fungi. Many of the active components isolated from plant extracts exert toxic activity against mosquito larvae ${ }^{[19,20,21,22]}$. In addition to this they can also be used as ovicidal, oviposition deterrents, growth and reproduction inhibitors ${ }^{[23,24]}$ or adult repellents ${ }^{[25]}$. Here we report the knockdown and repellent activity of essential oils extracted from selected plants against Culex quinquefasciatus Say. 


\section{Materials and methods \\ Collection of plants}

All the three plants tested are collected from in and around of Calicut University Campus, Malappuram, Kerala and are taxonomically identified from the Department of Botany, University of Calicut and presented in the table 1 below.

\section{Test organism}

Culex quinquefasciatus was selected as test organism. This species comes under Culex pipiens species complex and act as a potential vector of Wuchereria bancrofti causing filariasis and female mosquitoes host the filarial parasites.

\section{Extraction of essential oil}

Three aromatic plants were selected for essential oil extraction. Essential oils of selected plants were extracted by steam distillation method using Clevenger apparatus. The leaves of the plants were collected, washed and used for essential oil extraction using distilled water for $4 \mathrm{~h}$. The resulting essential oils were dried over anhydrous-sodium sulfate and used to conduct bioassays.

\section{Adulticidal bioassay}

The adulticidal activity of different concentrations of the selected essential oils are also estimated. The bioassay was performed by following WHO [26] protocol. Different concentrations of the oils were prepared by dissolving the oil in ethanol and applied on Whatman No. 1 filter papers. Control papers were treated with ethanol and distilled water under similar conditions. Twenty female mosquitoes (2-5 days old glucose fed, blood starved) each were collected from the insect-rearing cage and gently transferred into a plastic holding tubes. The mosquitoes were allowed to acclimatize in the tube for $1 \mathrm{~h}$ and then exposed to test paper (filter paper) for $1 \mathrm{~h}$. At the end of exposure period, the mosquitoes were transferred back to the holding tube and kept for $24 \mathrm{~h}$ for recovery period. Mortality of mosquitoes was determined at the end of $24 \mathrm{hr}$. The number of mosquitoes knocked down in the exposure tube was recorded at 5 min interval period till the last mosquito was knocked down. Knock down time (KDT) values of KDT50 and KDT90 were determined using probit analysis.

\section{Adult repellency test}

The repellent activity was conducted with slightly modified method of WHO ${ }^{[27]}$. Repellency bioassays were carried out in the laboratory at $27-35^{\circ} \mathrm{C}$ and $60-80 \% \mathrm{RH}$. Three to four days old blood-starved 100 adult females of Culex quinquefasciatus mosquito was randomly selected and placed in an experimental cage $(30 \times 30 \times 30 \mathrm{~cm})$ and left to acclimatize for $1 \mathrm{~h}$. The arms of the tested persons were cleaned with ethanol. After air drying the arm of the test person, only $25 \mathrm{~cm}^{2}$ dorsal side of the skin on each arm was exposed and the remaining area were covered with rubber gloves. The selected essential oils at different concentrations $(50,100,150,200$ and $250 \mathrm{ppm})$ was applied. The control and treated arms were introduced simultaneously into the cage. The first bite by Culex quinquefasciatus was noted from 5 minutes for every $1 \mathrm{~h}$ up to $6 \mathrm{~h}$. Subsequently, the test arm was introduced into the cage for the same period of time and the number of mosquitoes that landed and attempted to feed were recorded. Each experiment was conducted three times. It was observed that there was no skin irritation by the extracts of the selected essential oils. The percentage protection was calculated by using the following formula;

Percentage Protection - No. of bites received by control - No. of bites received by treated $\mathrm{X} 100$ No, of bites received by control

\section{Results}

Among selected plant extracts $C$. limon exhibited higher knockdown effect at minimum concentration followed by $L$. camara and $C$. verum. It was noted that the knockdown effects of all plant extracts are positively correlated with the concentration (Fig.1). C. limon consistently exhibited higher knockdown effect in all tested concentrations. All plants exhibited similar trend of activity except $C$. verum was more active than $L$. camara at $1 \%$ concentration.

It was found that the mosquito repellent activity of selected plant extracts is distinct in all concentrations (Figs2-6). Citrus limon exhibited maximum repellent activity in all concentrations. The selected plants exhibited 100 percent repellent activity only for one hour in case of concentration below 50\% (Figs $2 \& 3$ ). Later the repellent activity has been reduced gradually. From 50-70\% concentration the repellent activity of all plants persisted up to three hours exposure time (Figs $4 \& 5$ ). At $10 \%$ C. limon showed maximum repellent activity followed by $C$. verum and $L$. camara. The difference in the activity of $C$. verum and $L$. camara is found to be distinct between 5-6 hours of exposure (Fig. 2). At $25 \%$ concentration the increase in activity of $C$. verum was evident between 2-5 hours whereas at 6hour exposure of $L$. camara and $C$. verum showed almost similar activities (Fig. 3 ).

The repellent activity of selected plant extracts was found to be consistent up to 3 hours of exposure at $50 \%$ concentration.
Similarly, to lower concentrations the activity of $C$. verum found higher than L. camara (Fig. 4). At $70 \%$ concentration $C$. limon and $C$. verum exhibited maximum repellent activity up to 5 hours of exposure. It is noted that the repellent activity of L. camara decreased drastically after 4 hours of exposure (Fig. 5). At $100 \%$ concentration all plant extracts showed maximum activity up to 5 hours of exposure (Fig. 6). Likewise, to all concentrations the activity of $L$. camara was decreased considerably than C. verum (Fig. 6).

\section{Discussion}

Plant derived essential oils have been widely used to ensure protection from mosquitoes and other blood sucking insects ${ }^{[28]}$. All essential oils from selected plants showed remarkable knockdown activity against $C x$. quinquefasciatus. The results of the present study showed that $C$. limon exhibited higher knockdown effect in all concentrations than other essential oils tested. The increased activity of $C$. limon is supported by Soonwera ${ }^{[29]}$ as essential oil from eight Citrus plants showed higher knockdown effect against $C x$. quinquefasciatus and Aedes aegypti. Citrus limon exhibited higher knockdown activity in all the concentrations. The results showed that $C x$. quinquefasciatus is found to be susceptible towards essential oils derived from plants particularly from Citrus plants ${ }^{[29]}$. This result is further supported by Tawatsin et al. ${ }^{[30]}$ reporting essential oils from 18 plants belonging to 11 families found to 
be active against $C x$. quinquefasciatus. Apart from $C$. limon, other essential oils like L. camara and $C$. verum showed moderate activity against $C x$. quinquefasciatus. The activities of these plants are in line with the results of Dua et al. ${ }^{[31]}$ and Manimaran et al. ${ }^{[32]}$ as essential oil from $L$. camara and $C$. verum found effective against three mosquito species ( $A n$. stephensi, Cx. quinquefasciatus and Ae. aegypti).

Several plant-derived essential oils have been found as mosquito repellent by reducing the biting nuisance ${ }^{[33-37]}$. In the present study it was observed that all the essential oils exhibited considerable repellent activity against $C x$. quinquefasciatus at different concentrations. Among the selected plants, $C$. limon was found to be highly active. Essential oil from $C$. limon exhibited nearly $100 \%$ protection in all concentrations and the increased activity is comparable with that of Citrus aurantifolia, which exhibited an average of $98.3 \%$ protection from $C x$. quinquefasciatus. In addition to this, the potential for using Citrus derived essential oils as an alternative to synthetic repellent cannot be neglected.

Essential oils from Cinnamomum verum showed repellent activity at $50 \%$ concentration and the activity was extended up to 6 hours. The differential activity of Cinnamomum is supported by Prajapati et al. ${ }^{[38]}$ and reported that
Cinnamomum zeylanicum is found to be good candidate for using as repellent and adulticidal botanical against $C x$. quinquefasciatus. It was noted that the $100 \%$ repellent activity of the essential oils derived from Cinnamomum spp. (C. camphora and C. zeylanicum) against Anopheles stephensi ${ }^{[39]}$ and oils from $C$. zeylanicum exhibit one-hour protection from An. Subpictus ${ }^{[40]}$. Based on the effectiveness of essential oils derived from Cinnamomum species against $C x$. quinquefasciatus, it may be used as an effective control method for other mosquitoes as well. Essential oil from $L$. camara showed repellent activity similar to that of $C$. verum. From the results of the present study, it was evident that essential oils derived from plants are found to be a good alternative to synthetic repellents with their promising knockdown and repellent activity against $C x$. quinquefasciatus. However, for practical use of these essential oils, further research should be done to rule out if any problem still exist in order to address with human safety. Present study also delivers important information on the plant based essential oils and their differential activity against $C x$. quinquefasciatus. Considering all these, it can be inferred that the essential oils derived from these plants could be used effectively against mosquito vectors.

Table 1: Lists of plants collected from different localities from the campus of the University of Calicut, Kerala

\begin{tabular}{|c|c|c|c|}
\hline Name of the Plant & Common Name & Family & Part used \\
\hline Cinnamomum verum Schaeff. & Cinnamon & Lauraceae & Leaves \\
\hline Citrus limon (L.) Osbeck & Citrus & Rutaceae & Leaves \\
\hline Lantana camara L. & Nil & Verbenaceae & Leaves \\
\hline
\end{tabular}

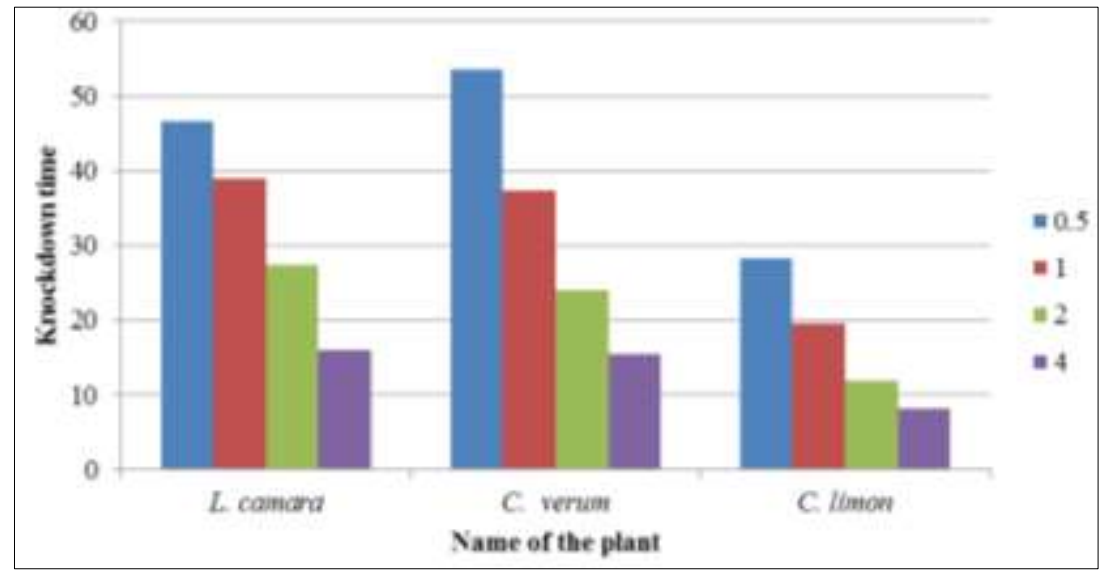

Fig 1: Knock down times required to kill $50 \%$ of the population exposed. $0.5,1,2$ and 4 are different concentrations in $\%$ treated for the study

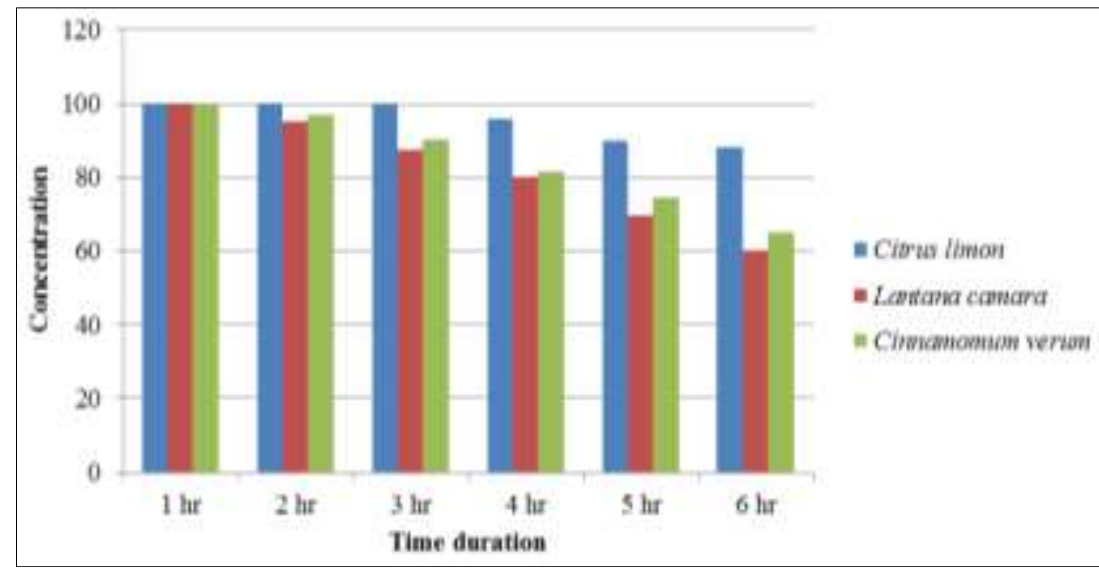

Fig 2: Adult repellency test using 10\% volatile oils for 1-6 hours of application 


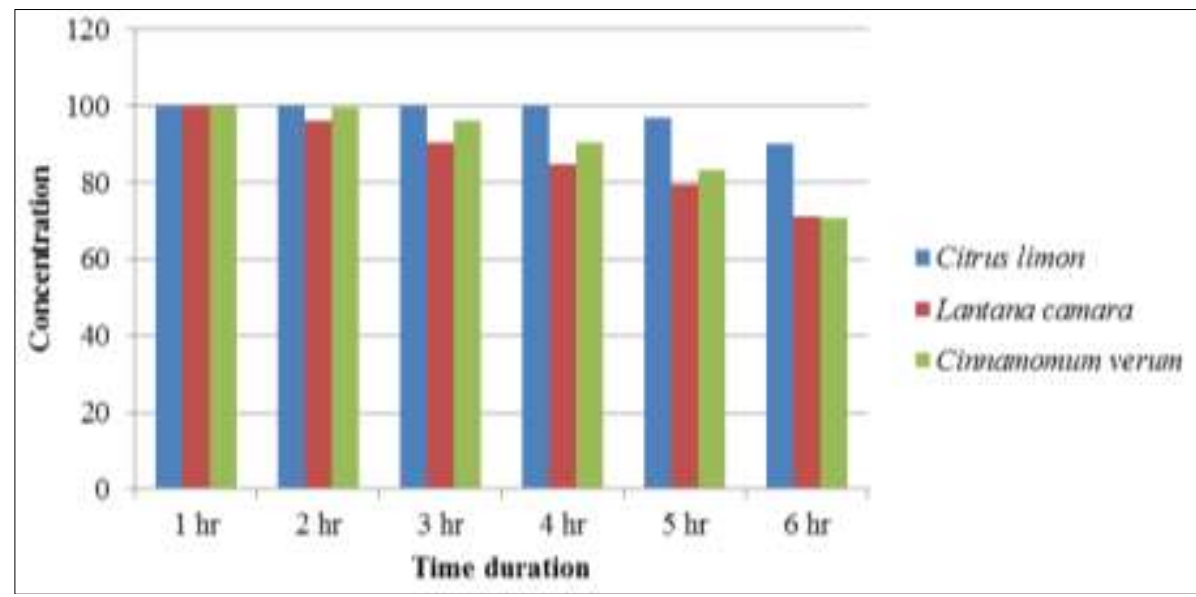

Fig 3: Adult repellency test using $25 \%$ volatile oils for 1-6 hours of application

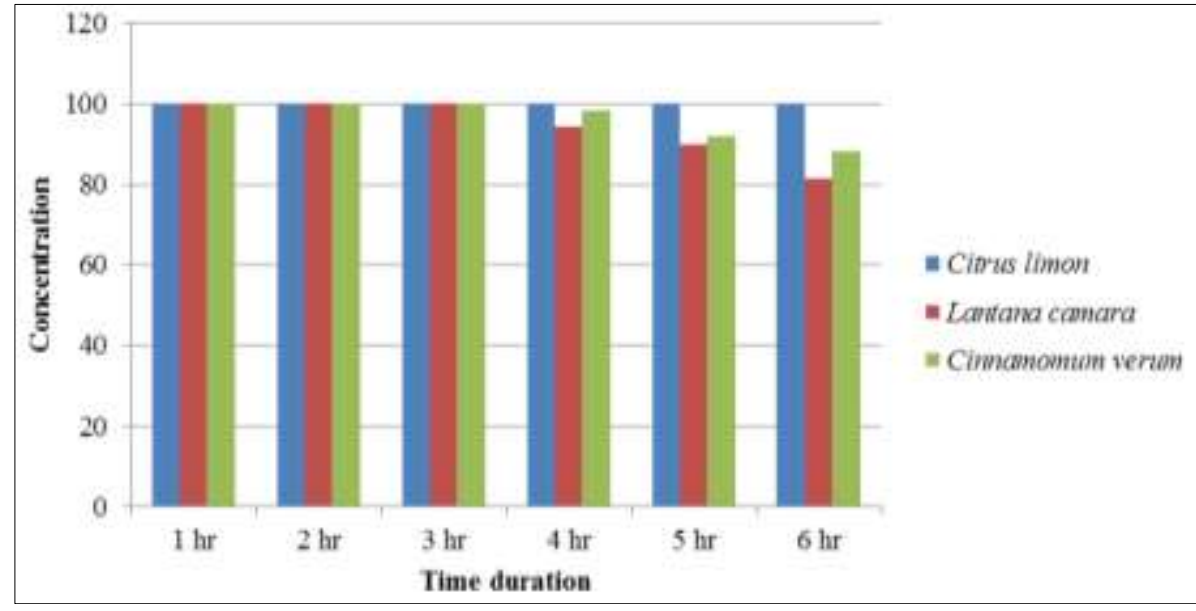

Fig 4: Adult repellency test using 50\% volatile oils for 1-6 hours of application

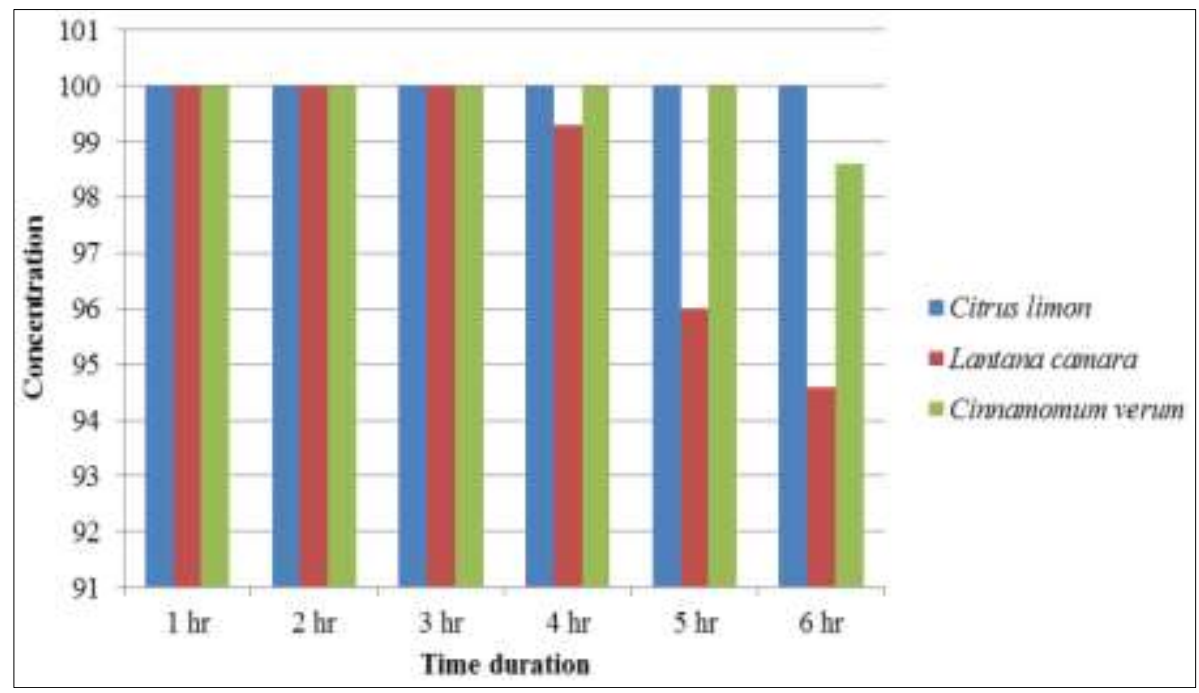

Fig 5: Adult repellency test using 70\% volatile oils for 1-6 hours of application 


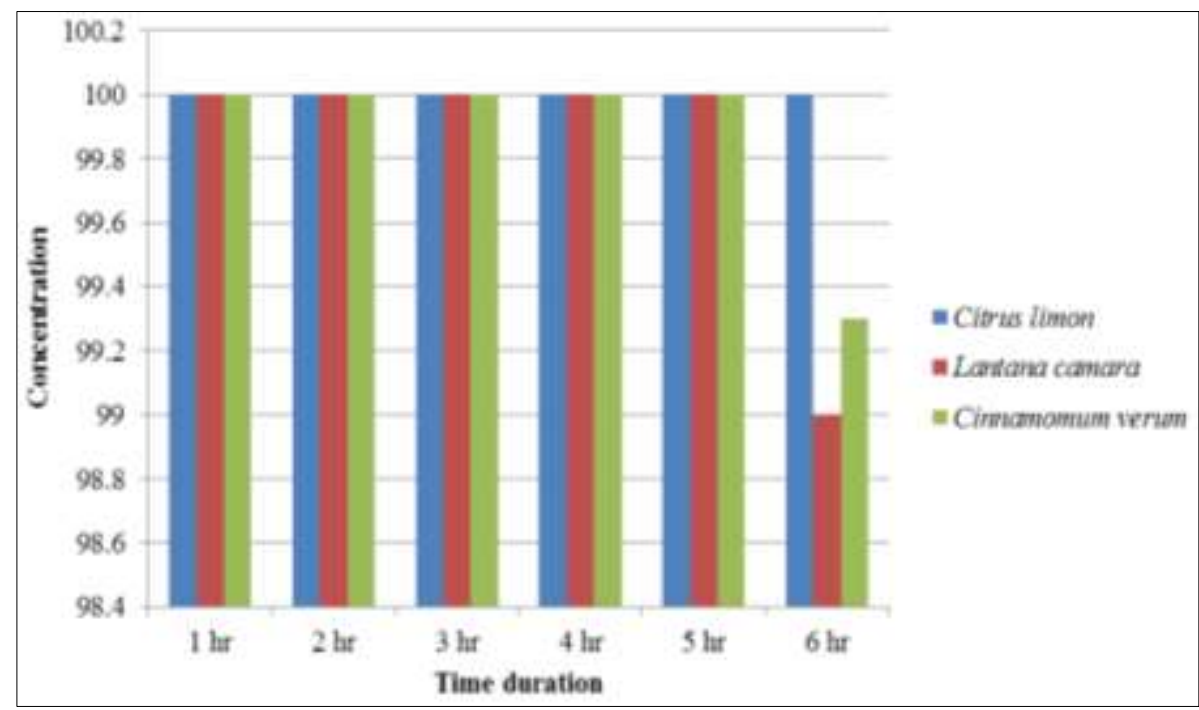

Fig 6: Adult repellency test using 100\% volatile oils for 1-6 hours of application

\section{Acknowledgements}

Authors acknowledge University Grants Commission, New Delhi for the financial support through UGC-MRP programme.

\section{References}

1. Sakulku U, Nuchuchua O, Uawongyart N, Puttipipatkhahorn S, Soottitantawat A, Ruktanonchai U. Characterization and repellent activity of citronella oil nanoemulsiom. Int. J Pharm 2009;327:105-111.

2. WHO. Dengue and dengue haemorrhagic fever. Retrieved from 2011 http://www.who.int/mediacentre/fastsheets

3. James AA. Mosquito molecular genetics: the hands that feed bite back. Science 1992;257(5066):37-38.

4. Peng Z, Yang J, Wang H, Simons FER. Production and characterization of monoclonal antibodies to two new mosquito Aedes aegypti salivary proteins. Ins. Biochem. Mol. Biol 1999;29(10):909-914.

5. Yang YC, Lee SG, Lee HK, Kim MK, Lee SH, Lee HS. A piperidine amide extracted from Piper longum L. fruit shows activity against Aedes aegypti mosquito larvae. J Agric. Food Chem 2002;50(13):3765-3767.

6. Brogdon WG, Mcallister JC. Insecticide resistance and vector assays to detect and assess resistance in Trinidadian strains of Aedes aegypti control. Emerg. Infect. Dis 1998;4:605-613.

7. Brown AWA. Insecticide resistance in mosquitoes: a pragmatic review. J Am. Mos. Contr. Assoc 1986;2:123139.

8. Severini C, Romi R, Marinucci M, Rajmond M. Mechanism of insecticide resistance in field populations of Culex pipiens from Italy. J Am. Mosq. Control. Assoc 1993;9:164-168.

9. Soonwera M. Efficacy of essential oils from Citrus plants against mosquito vectors Aedes aegypti (Linn.) and Culex quinquefasciatus (Say). Int. J Agri. Tech 2015;11(3):669681.

10. Sukumar K, Perich MJ, Boobar LR. Botanicalderivatives in mosquito control: a review. J Am. Mosq. Control. Assoc 1991;7:210-237.

11. Watanabe K, Shono Y, Kakimizu A, Okada A, Matsuo N, Satoh A et al. New mosquito repellent from Eucalyptus camalduensis. J Agric. Food. Chem 1993;41:2164-2166.

12. Wink M. Production and application of phytochemicals from an agricultural perspectives. In: van Beek TA and Breteler H, eds. Phytochemistry and agriculture. Oxford, United Kingdom: Clarendon Press 1993, 171-213.

13. Chattopadhyay $\mathrm{P}$, Dhiman S, Borah S, Rabha B, Chaurasia AK, Veer V. Essential oil based polymeric patch development and evaluating its repellent activity against mosquitoes. Acta. Trop 2015;147:45-53.

14. Dhiman S, Rabha B, Chattopadhyay P, Das NG, Hazarika $\mathrm{S}$, Bhola RK et al. Field evaluation of repellency of a polyherbal essential oil against blackflies and its dermal toxicity using rat model. Trop. Biomed 2012;29:391-397.

15. Hazarika S, Dhiman S, Rabha B, Bhola RK, Singh L. Repellent activity of some essential oils against simulium species in India. J Insect Sci 2012;12:5.

16. Tripathi AK, Upadhyay S, Bhuiyan M, Bhattacharya PR. A review on prospects of essential oils as biopesticide in insect-pest management. J Pharmacogn. Phytother 2009;1:52-63.

17. Kim SI, Shin OK, Song C, Cho KY, Ahn YJ. Insecticidal activities of aromatic plant extracts against four agricultural insects. Agric. Chem. Biotechnol 2001;44(1):23-26.

18. Cheng SS, Liu JY, Tsai KH, Chen WJ, Chang ST. Chemical composition and mosquito larvicidal activity of essential oils from leaves of different Cinnamomum osmophloeum provenances. J Agric. Food Chem 2004;52:4395-4400.

19. Rahuman AA, Venkatesan P, Gopalakrishnan G. Mosquito larvicidal activity of oleic and linoleic acids isolated from Citrullus colocynthis (Linn.) Schrad. Parasitol. Res 2008;103:1383-1390.

20. Mathew N, Anitha MG, Bala TSL, Sivakumar SM, Narmadha R, Kalyanasundaram M. Larvicidal activity of Saraca indica, Nyctanthes arbor-tristis and Clitoria ternatea extracts against three mosquito vector species. Parasitol. Res 2009;104:1017-1025.

21. Conti B, Canale A, Bertoli A, Gozzini F, Pistelli L. Essential oil composition and larvicidal activity of six Mediterranean aromatic plants against the mosquito Aedes albopictus (Diptera: Culicidae). Parasitol. Res 2010;107:1455-1462. 
22. Hafeez F, Akram W, Shaalan EA. Mosquito larvicidal activity of citrus limonoids against Aedesalbopictus. Parasitol Res 2011;109:221-229.

23. Rajkumar S, Jebanesan A. Repellency of volatile oils from Moschosma polystachyum and Solanum xanthocarpum against filarial vector Culex quinquefasciatus Say. Tropical. Biomed 2005;22:139142.

24. Pushpanathan T, Jebanesan A, Govindarajan M. Larvicidal, ovicidal and repellent activities of Cymbopogan citrates Stapf (Graminae) essential oil against the filarial mosquito Culex quinquefasciatus (Say) (Diptera: Culicidae). Tropical. Biomed 2006;23:208-212.

25. Gleiser RM, Bonino MA, Zygadlo JA. Repellence of essential oils of aromatic plants growing in Argentina against Aedesaegypti. Parasitol. Res 2011;108:69-78.

26. WHO. Report of the WHO informal consultation on the evaluation on the testing of insecticides. CDT/WHO PES/IC/1996;96(1):69.

27. WHO. Guidelines for efficacy testing of mosquito repellents for human skin. WHO/HTM/NTD/WHOPES/2009.4. Control of neglected tropical diseases, World Health Organization, Geneva 2009.

28. Dua VK, Pandey AC, Dash AP. Adulticidal activity of essential oil of Lantana camara leaves against mosquitoes. Ind. J Med. Res 2010;131:434-439.

29. Soonwera M. Efficacy of essential oils from Citrus plants against mosquito vectors Aedes aegypti (Linn.) and Culex quinquefasciatus (Say). Int. J Agri. Tech 2015;11(3):669681.

30. Tawatsin A, Asavadachanukorn P, Thavara U, Wongsinkongman $\mathrm{P}$, Bansidni $\mathrm{J}$, Boonruad $\mathrm{T}$ et al. Repellency of essential oils extracted from plants in Thailand against four mosquito vectors (Diptera: Culicidae) and oviposition deterrent effects against Aedesaegypti (Diptera: Culicidae). South. Asi. J Trop. Med. Pub. Heal 2006;39:915-931.

31. Dua VK, Pandey AC, Dash AP. Adulticidal activity of essential oil of Lantana camara leaves against mosquitoes. Ind. J Med. Res 2010;131:434-439.

32. Manimaran A, Cruz MMJJ, Muthu C, Vincent S, Ignacimuthu S. Larvicidal and knockdown effects of some essential oils against Culex quinquefasciatus Say, Aedesaegypti (L.) and Anopheles stephensi (Liston). Adv. Biosci. Biotech 2012;3:855-862.

33. Adeniran OI, Fabiyi EA. Cream formulation of an effective mosquito repellent: A topical product from lemongrass oil (Cymbopogon citratus) Stapf. J Nat. Prod. Plant Resour 2012;2:322-327.

34. Bakr RFA, El Bermawy SM, Geneidy NAM, Emara SA, Hassan HW. Occurrence of the biological effects of some plant extracts on the cotton leaf worm Spodoptera littoralis (Biosd) and their physiological. J Egypt Acad. Soc. Environ. Dev 2006;7:109-147.

35. Conti B, Leonardi M, Pistelli L, Profeti R, Ouerghemmi I, Benelli G. Larvicidal and repellent activity of essential oils from wild and cultivated Ruta chalepensis L. (Rutaceae) against Aedes albopictus Skuse (Diptera: Culicidae), an arbovirus vector. Parasitol. Res 2013;112:991-999.

36. Das NG, Dhiman S, Talukdar PK, Rabha B, Goswami D, Veer V. Synergistic mosquito-repellent activity of
Curcuma longa, Pogostemon heyneanus and Zanthoxylum limonella essential oils. J Infect. Pub, Heal 2015;8(4):323-328.

37. Lawal HO, Adewuyi GO, Fawehinmi AB, Adeogun AO, Etatuvie SO. Bioassay of herbal mosquito repellent formulated from the essential oil of plants. J Nat. Prod 2012;5:109-115.

38. Prajapati V, Tripathi AK, Aggrawal KK, Khanuja SPS. Insecticidal, repellent and oviposition deterrent activity of selected essential oils against Anopheles stephensi, Aedes aegypti and Culex quinquefasciatus. Bioresour. Technol 2005;96:1749-1757.

39. Amer A, Mehlhorn H. Larvicidal effects of various essential oils against Aedes, Anopheles, and Culex larvae (Diptera, Culicidae). Parasitol. Res 2006;99:466-472.

40. Govindarajan M, Mathivanan T, Elumalai K, Krishnappa K, Anandan A. Mosquito larvicidal, ovicidal, and repellent properties of botanical extracts against Anopheles stephensi, Aedes aegypti, and Culex quinquefasciatus (Diptera: Culicidae). Parasitol. Res 2011;109:353-367. 